Personality and Individual Differences

Elsevier Editorial system(tm) for

Manuscript Draft

Manuscript Number: PAID-D-16-00260R2

Title: The utility of the MMPI-2-RF to predict the outcome of a smokingcessation treatment

Article Type: Full Length Article

Section/Category: Research Paper ( $<5000$ words)

Keywords: MMPI-2-RF; tobacco; smoking cessation; smokers; psychopathology

Corresponding Author: Dr. Ursula Martinez, Ph.D.

Corresponding Author's Institution: Universidade de Santiago de Compostela

First Author: Ursula Martinez, Ph.D.

Order of Authors: Ursula Martinez, Ph.D.; Elena Fernández del Río, PhD.; Ana López-Durán, PhD.; Elisardo Becoña, PhD.

Abstract: People with psychopathology experience high rates of smoking and have more trouble quitting. The Minnesota Multiphasic Personality Inventory-2 Restructured Form (MMPI-2-RF; Tellegen \& Ben-Porath, 2008/2009) is a valid and reliable instrument for the assessment of psychopathology. In this study, we examined the ability of the MMPI-2-RF to assess psychopathology and to predict smoking cessation outcomes in a sample of 281 smokers seeking psychological treatment to stop smoking at the end of treatment and at 6- and 12-month follow-ups. Results showed that T-scores < 65 on Disaffiliativeness (DSF) scale were associated with a higher likelihood of smoking at the end of treatment, and T-scores $\geq 65$ on Neurological Complaints (NUC) scale were associated with a higher likelihood of smoking at the 12-month follow-up, after controlling for the effect of age and initial levels of nicotine dependence. The results highlight the usefulness of the MMPI-2-RF in the field of smoking cessation treatment. 


\section{THE UTILITY OF THE MMPI-2-RF TO PREDICT THE OUTCOME OF A}

\section{SMOKING-CESSATION TREATMENT}

Úrsula Martínez ${ }^{\mathrm{a}}$, Elena Fernández del Río ${ }^{\mathrm{a}, \mathrm{b}}$, Ana López-Durán ${ }^{\mathrm{a}}$, and Elisardo Becoña ${ }^{\mathrm{a}}$ ${ }^{a}$ Smoking and Addictive Disorders Unit, Faculty of Psychology, Department of Clinical Psychology and Psychobiology, University of Santiago de Compostela, Spain.

${ }^{\mathrm{b}}$ Department of Psychology and Sociology, Faculty of Social Sciences and Work, University of Zaragoza, Spain.

Corresponding Author:

Úrsula Martínez. Smoking Cessation and Addictive Disorders Unit. Faculty of Psychology. Campus Vida. 15782 Santiago de Compostela. Spain

Phone: (+34) 881813939

E-mail: ursula.martinez@usc.es 
- Psychopathology influences smoking cessation treatment.

- The MMPI-2-RF is a valid and reliable instrument to assess phychopathology.

- The scales of the MMPI-2-RF are used to predict smoking in smokers seeking treatment.

- DSF and NUC scales predict smoking at the end of treatment and after 12 months. 
1

\section{Abstract}

People with psychopathology experience high rates of smoking and have more trouble quitting. The Minnesota Multiphasic Personality Inventory-2 Restructured Form (MMPI-2-RF; Tellegen \& Ben-Porath, 2008/2009) is a valid and reliable instrument for the assessment of psychopathology. In this study, we examined the ability of the MMPI2-RF to assess psychopathology and to predict smoking cessation outcomes in a sample of 281 smokers seeking psychological treatment to stop smoking at the end of treatment and at 6- and 12-month follow-ups. Results showed that $T$-scores $<65$ on Disaffiliativeness (DSF) scale were associated with a higher likelihood of smoking at the end of treatment, and $T$-scores $\geq 65$ on Neurological Complaints (NUC) scale were associated with a higher likelihood of smoking at the 12-month follow-up, after controlling for the effect of age and initial levels of nicotine dependence. The results highlight the usefulness of the MMPI-2-RF in the field of smoking cessation treatment. Key words: MMPI-2-RF, tobacco, smoking cessation, smokers, psychopathology 


\section{Introduction}

Tobacco use is the leading preventable cause of morbidity and mortality in high income countries. Nearly six million people worldwide die each year because of tobacco due to its direct relation with different diseases (e.g., lung cancer, cardiovascular disorders, emphysema, etc.) (United States Department of Health and Human Services [USDHHS], 2014).

Evidence indicates that smoking is also related to mental health (Aubin, Rollema, Svenson, \& Winterer, 2012; Hall, \& Prochaska, 2009; Rüther et al., 2014). In a study conducted by Lasser et al. (2000) adults with and without mental disorders were compared regarding their smoking rates and cessation. The results indicated a doseresponse pattern with smoking rates increasing from individuals with no mental disorders to those with past month mental disorders. The same pattern was found when assessing smoking cessation outcomes: abstinence rates were higher in those participants with no mental disorders and they decreased progressively in those with history of mental disorders and those with past month mental disorders.

People with mental disorders smoke more cigarettes per day and are more nicotine dependent (Aubin et al., 2012) with rates of smoking prevalence from two to four times higher than in the general population (Rüther et al., 2014). The reasons for this high consumption are still unknown. It has been indicated that they might smoke for stress relief and enjoyment, to ameliorate the effects of mental health problems and medication side effects, to relief boredom or as a tool to facilitate social interactions (Campion, Checinski, Nurse, \& McNeill, 2008). As a result of this high consumption, people with mental disorders have serious physical health problems. Moreover, studies suggest that people with mental disorders have more problems quitting smoking, showing lower abstinence rates in comparison with the general population (Hall \& 
Prochaska, 2009). Despite the need for people with mental disorders to stop smoking, few studies have evaluated the efficacy of smoking cessation treatments in patients with mental disorders (Aubin et al., 2012). Among them, the majority has focused in the population of smokers with severe mental disorders (e.g., schizophrenia, bipolar disorders). This indicates that more studies are needed for those smokers without a diagnosis of mental disorder but who suffer an important level of distress to influence their smoking and their smoking cessation.

One of the difficulties in the study of psychopathology in smokers is the diversity of assessment tools used. Historically, the Minnesota Multiphasic Personality Inventory (MMPI; Hathaway, \& McKinley, 1943) has been the most commonly used measure to assess psychopathology. In studies with the MMPI or the MMPI-2, a relationship has been found between tobacco and high scores on the Hypomania (Ma) (Basile et al., 2004; Evans, Borgatta, \& Bohrnstedt, 1967; Lipkus, Barefoot, Williams, \& Siegler, 1994), Psychopathic Deviate (Pd) (Andrucci, Archer, Pancoast, \& Gordon, 1989; Evans et al., 1967; Jaffe, \& Archer, 1987; Leon, Kolotkin, \& Korgeski, 1979; Lipkus et al., 1994), Hypochondriasis (Hs) (Tappan, \& Weybrew, 1982), and Depression (D) (Leon et al., 1979) scales. Ames et al. (2005) used various MMPI scales to assess neuroticism, anxiety, depression and pessimism traits to predict tobacco abstinence in 1,877 smokers undergoing treatment to quit smoking. The results showed that high scores on these scales were associated with a lower likelihood of being abstinent six months after treatment completion. In general, these studies employed some items or scales of the questionnaire, but not the entire scale, and they mainly used samples of students, making it difficult to generalize these results to other populations. The MMPI-2-RF (Tellegen, \& Ben-Porath, 2008/2009) is the latest version of the MMPI. It is a self-report questionnaire composed of 338 items grouped into scales 
that are organized hierarchically. Studies have indicated that the scales within the MMPI-2-RF had good convergent and discriminant validity (Ayearst, Sellbom, Trobst, \& Bagby, 2013; Tellegen, \& Ben-Porath, 2008/2009) and it has been found to be useful for the assessment of psychopathology (Simms, Casillas, Clark, Watson, \& Doebbeling, 2005; van der Heijden, Egger, \& Derksen, 2008). However, to our knowledge, no research is available on the assessment of smokers seeking treatment to quit. Taking into account the high comorbidity of psychopathology and personality problems with smoking and its influence on the process of quitting smoking, using the MMPI-2-RF in the context of smoking cessation interventions would be useful to identify, in a relatively simple way, those smokers with a higher risk for psychopathological problems and treatment failure that may need more attention.

Thus, the aim of this study was to analyze the utility of the MMPI-2-RF scales, as indicators of psychopathology, in the prediction of the outcome of a smoking cessation treatment, both at the end of treatment and at the 6 and 12 month follow-ups.

\section{Method}

\subsection{Participants}

Sociodemographic characteristics of participants are presented in Table 1. All participants requested treatment to quit smoking between April 2010 and December 2012. Of the 594 people who requested information, 134 just wanted information about the program, 10 were abstinent, 47 were interested in the smoking cessation intervention by mail (which is also offered by our Unit), and 19 were not located. Finally, 99 smokers were eliminated from the study, due to the following exclusion criteria: age under $18(n=4)$; smoking fewer than 10 cigarettes a day $(n=21)$; not completing the pretreatment assessment $(n=36)$; diagnosis of a severe mental disorder (bipolar disorder and/or psychotic disorder) $(n=14)$; concurrent dependence on other 
substances (alcohol, cannabis, cocaine, heroin, etc.) $(n=6)$; smoking rolling tobacco, cigars, or cigarillos $(n=3)$; having participated in the same program or other efficacious psychological or pharmacological treatments to quit smoking in the past year $(n=7)$; suffering from some pathology that implies a high life risk for the person $(n=3)$; and not attending the first group session $(n=5)$. Of the remaining 285,4 were eliminated from the study because they presented an invalid MMPI-2-RF protocol according to the recommended criteria (CNS $\geq 18, \mathrm{TRIN} \geq 80, \mathrm{VRIN} \geq 80, \mathrm{~F}-\mathrm{r} \geq 120, \mathrm{Fp}-\mathrm{r} \geq 100$ ) (Tellegen, \& Ben-Porath, 2008/2009). The final sample comprised 281 smokers $(60.5 \%$ women; $M=41.80$ years, $S D=10.78$ ), with an average pretreatment consumption of 21.36 cigarettes per day $(S D=7.92)$.

Table 1 about here-

\subsection{Measures}

\subsubsection{Questionnaire about the smoking behavior (Becoña, 1994).}

Composed of 59 items analyzing sociodemographic variables and various aspects of the smoking history and behavior.

\subsubsection{Fagerström Test for Nicotine Dependence (FTND) (Heatherton, Kozlowski,} Frecker, \& Fagerström, 1991; adaptation to Spanish of Becoña, \& Vázquez, 1998). Composed of six items in which scores $\geq 6$ are considered to be indicative of nicotine dependence (Fagerström, \& Furberg, 2008). In the current study, the reliability obtained with Cronbach's alpha coefficient was .59 , indicating that it has moderate internal consistency, in accordance with previous studies (e.g., John, Meyer, Rumpf, \& Hapke, 2004).

\subsubsection{MMPI-2-RF (Tellegen, \& Ben-Porath, 2008/2009).}

A 338-item self-report questionnaire that provides scores on 51scales. First, there is a group of 9 scales for the assessment of validity. On the other hand a group of 
five scales, the Personality Psychopathology Five (PSY-5), assess personality, aggressiveness, psychoticism, disconstraint, negative emotionality, and introversion. In addition, two scales measure aesthetic-literary or mechanical-physical interests. Finally, measures of psychopathology are organized hierarchically. The Higher-Order $(\mathrm{H}-\mathrm{O})$ scales, which define the highest level, provide an organizational structure, the Restructured Clinical (RC) scales, which are in an intermediate level and analyze clinical features, and at the bottom of the hierarchy, the Specific Problems (SP) scales that provide a more fully developed and detailed assessment. The H-O scales are three scales for the assessment of emotional or internalization dysfunction, thought dysfunction and behavioral or externalizing dysfunction. The RC scales, are a group of 9 scales that assess demoralization, somatic complaints, low positive emotions, cynicism, antisocial behavior, ideas of persecution, dysfunctional negative emotions, aberrant experiences, and hypomanic activation. The SP scales are 23 and they are divided in four groups for the assessment of somatic/cognitive problems, internalizing problems, externalizing problems, and interpersonal problems. Reliability and validity of this instrument are good, and extensive data can be consulted in the MMPI-2-RF Technical Manual (Tellegen \& Ben-Porath, 2008/2009). T scores of $\geq 65$ are considered to be indicative of psychopathology (Tellegen \& Ben-Porath, 2008/2009).

\subsection{Procedure}

All the participants were assessed with all the above-mentioned questionnaires in a face-to-face interview. All the smokers gave their informed consent for participation, and the study was authorized by the Bioethics Committee.

After the assessment, participants started the Smoking Cessation Program (Becoña, 2007). It is a cognitive-behavioral intervention consisting of six sessions (one per week) administered in groups made-up of 4-10 participants assigned according to 
their availability. It contains the following elements: treatment contract, self-report and graphic representation of cigarette consumption, information about tobacco, stimulus control, activities to avoid the withdrawal syndrome, physiological feedback (CO in expired air) on cigarette consumption, nicotine fading (change of cigarette brands each week progressively decreasing the intake of nicotine and tar), and relapse-prevention strategies.

Face to face follow-ups were conducted 6 and 12 months after treatment. In those cases in which participants could not be located, they were considered to be smokers.

\subsection{Abstinence measures}

We used the Micro ${ }^{+}$Smokerlyzer ${ }^{\circledR}$ (Bedfont Scientific Ltd, Sittingbourne, UK) to measure carbon monoxide $(\mathrm{CO})$ in expired air, to corroborate self-reported abstinence at the end of treatment and at the 6- and 12-month follow-ups (cut-off point of $<10 \mathrm{ppm}$ to be considered a non-smoker) (West, Hajek, Stead, \& Stapleton, 2005). A participant was considered abstinent when he or she reported not smoking for at least 24 hours at the end of treatment, during the 7 days prior to the date of the 6-month follow-up, and 30 days prior to the 12-month follow-up (Velicer, Prochaska, Rossi, \& Snow, 1992).

\subsection{Statistical Analysis}

To determine sample characteristics, we conducted descriptive statistical analysis. To test the differences between abstainers and smokers at the end of treatment and at the 6- and 12-month follow-ups, we used Pearson's chi-square statistic (Cramer's V effect size was presented when chi-square was significant). We used binary logistic regression analysis with a stepwise procedure to identify the predictive value of psychopathology, assessed with the MMPI-2-RF scales adjusted for sociodemographic 
characteristics and nicotine dependence, on smoking status $(1=\mathrm{Yes}, 0=\mathrm{No})$ at the end of treatment and at 6- and 12-month follow-ups.

All analyses were performed with the SPSS software version 20 . The significance level was set at $\leq .05$.

\section{Results}

Treatment outcomes are reported in Table 2. -Table 2 about here-

Bivariate analyses (Table 2) indicated that there were significant differences according to age, nicotine dependence, and several scales of the MMPI-2-RF at the different assessment time points. Sex, educational level, and social class were not significant. With regard to the association between the MMPI-2-RF scales and smoking status, participants with $T$-scores $\geq 65$ on Emotional/ Internalizing Dysfunction (EID), Demoralization (RCd), Ideas of Persecution (RC6), Malaise (MLS), Cognitive Complaints (COG), Self-Doubt (SFD), Inefficacy (NFC), Anxiety (AXY), Disaffiliativeness (DSF), and Psychoticism-Revised (PSYC-r) were more likely to smoke at the end of treatment.

Regarding the 6- and 12-month follow-ups, there were a higher percentage of smokers than non-smokers with $T$-scores $\geq 65$ on Somatic Complaints (RC1) and Neurological Complaints (NUC).

The results of the binary logistic regression adjusted for age and nicotine dependence, showed that participants with T-scores $<65$ on Disaffiliativeness (DSF) $(\mathrm{OR}=0.145)$ had a higher likelihood of smoking at the end of treatment. No scale was significant in the prediction at the 6-month follow-up (Table 3). At the 12-month follow-up, participants with a $T$-score $\geq 65$ on Neurological complaints (NUC) (OR = 5.601) had a greater likelihood of smoking. 


\section{Discussion}

The aim of the present study was to analyze the utility of the MMPI-2-RF scales, as indicators of psychopathology, to predict the result of a treatment to quit smoking at the end of treatment and at the 6- and 12-month follow-ups.

At the end of treatment, there was a relationship between continuing to smoke and $T$-scores $\geq 65$ on the scales EID, RCd, RC6, MLS, COG, SFD, NFC, AXY, DSF, and PSYC-r. At the 6- and 12-month follow-ups, smoking was associated with $T$-scores $\geq 65$ on the RC1 and NUC scales. Moreover, T scores $\geq 65$ on DSF predicted being abstinent at the end of treatment, and T scores $\geq 65$ on NUC predicted smoking at the 12-month follow-up.

These results differ from those of Ames et al. (2005) who found that high scores on Scale 7 (Psychasthenia, Pt) and on Psychopathology Five-Negative Emotionality/Neuroticism (NEGE), referred to as Dysfunctional Negative Emotions (RC7) and Negative Emotionality/Neuroticism-revised (NEGE-r), respectively, in the most recent version of the MMPI-2-RF, were predictive of a lower likelihood of tobacco abstinence 6 months after receiving smoking cessation treatment. In contrast to our study, these authors only used some of the MMPI scales to assess traits such as anxiety, depression, pessimism, and neuroticism, which could explain the discrepancies with our results.

It is difficult to make comparisons with previous studies because many of them used very specific samples like people with a heart transplantation (Basile et al., 2004), submarine crews (Tappan \& Weybrew, 1982), or students (Andrucci et al., 1989; Evans et al., 1967; Jaffe, \& Archer, 1987; Lipkus et al., 1994). However, the above studies 
found high levels of psychopathology, as indicated by high scores on the MMPI in treatment seeking smokers (Ames et al., 2005; Cottraux et al., 1986).

Regarding the $\mathrm{H}-\mathrm{O}$ scales, a $T$-score $\geq 65$ on EID scale is related to not quitting at the end of treatment. Van der Heijden et al. (2012) also found high mean scores on this scale in 205 alcohol-dependent patients. These results could be a reflection of the emotional distress of people requesting treatment for substance use (Grant, Stinson et al., 2004), which could negatively affect treatment to quit smoking (Hitsman et al., 2013).

Within the group of RC scales, at the end of treatment, the results showed that $T$ scores $\geq 65$ on RCd and RC6 are related to smoking. As noted by Forbey and BenPorath (2007), people coming for substance abuse treatment often experience anxiety and distress and, as a result, they obtain high scores on multiple clinical scales, including some unexpected ones like the scale currently known as RC6, which is a measure of ideas of persecution. Van der Heijden, Egger, Rossi, \& Derksen (2012) also found high mean scores on the RC6 scale in the sample of alcohol-dependent patients. Although paranoid thoughts have been associated with the presence of psychotic disorders (Purdon, Purser, \& Goddard, 2011), they could be the result of ruminative thinking (Brinker, Chin, \& Wilkinson, 2014; Wolf et al., 2008), perhaps due to a low mood or an underlying anxiety disorder, both frequent disorders in smokers (Grant, Hasin, et al. 2004).

With regard to the 6- and 12-month follow-ups, high scores on the $\mathrm{RC} 1$ scale were related to smoking, as Forbey and Ben-Porath (2007) had found in their study with people in treatment for substance abuse. This scale assesses physical health problems. Forbey and Ben-Porath concluded that the high scores were due to the age of the participants of the sample $(M=44.4, S D=8.34)$, which could be applicable to our 
sample $(M=41.80, S D=10.78)$. It is known that smokers have a poorer physical health-related quality of life compared to never smokers or former smokers (Tian et al., 2016).

Within the SP scales, high scores on MLS, COG, SFD, NFC, AXY, and DSF were associated with smoking at the end of treatment, and the NUC scale was related to smoking at the 6- and 12-month follow-ups. These results cannot be compared with previous studies because, so far, no study has used the SP scales to assess smokers or people who use other substances. We found that a $T$-score $<65$ on DSF was associated with a greater likelihood of smoking at the end of treatment, and a $T$-score $\geq 65$ on NUC was associated with a greater likelihood of smoking at the 12-month follow-up.

High scores on DSF describe a person who dislikes people or being around them (Tellegen \& Ben-Porath, 2008/2009), and this scale has been linked to schizoid personality disorder (Ayearst et al., 2013; Ben-Porath, 2012; Tellegen \& Ben-Porath, 2008/2009). Piñeiro, Fernández del Río, López-Durán, Martínez, and Becoña (2013) found that people with schizoid personality disorder were more likely to maintain abstinence at the 6-and 12-month follow-ups after smoking cessation treatment. Also, Becoña, Fernández del Río, López-Durán, Piñeiro, and Martínez (2013) found that people with schizoid personality disorder were less likely to be nicotine-dependent smokers in a study with smokers of the general population. They concluded that smokers with schizoid personality disorder are more likely to experiment with tobacco but less likely to be dependent, which increases the likelihood of success when quitting (Fiore et al., 2008). In addition, schizoid personality disorder is characterized by a low need for stimulation (Ekleberry, 2009; Samuel \& Widiger, 2008) and for social relations, which would reduce the importance of social pressure to consume tobacco 
(Piñeiro et al., 2013) and would therefore present fewer problems to stop smoking and remain abstinent.

Regarding the NUC scale, $T$-scores $\geq 65$ predicted smoking at the 12-month follow-up. It has been suggested that a high score on this scale does not necessarily imply a neurological impairment (Ben-Porath, 2012; Bolinger, Reese, Suhr, \& Larrabee, 2014) but rather the presence of somatic and psychological problems (Bolinger et al., 2014). In fact, high scores on this scale in patients with major depressive disorder have been found (Sellbom, Bagby, Kushner, Quilty, \& Ayearst, 2012), and a positive correlation with rumination (Brinker et al., 2014), so it is possible that the relationship between high scores on the NUC scale and smoking is due to negative mood rather than to a neurological impairment.

Finally, in the PSY-5 scales, we found an association between $T$-scores $\geq 65$ on PSYC-r and tobacco consumption. Ames et al. (2005) used the Negative Emotionality/Neuroticism (NEGE) scale as a measure of neuroticism, finding that high scores on this scale were predictors of tobacco use 6 months after smoking cessation treatment. However, these authors did not use the other PSY-5 scales in their study. In our study, it is likely that the results are consistent with our previous comments about the relationship between persecutory ideas and low affect (Brinker et al., 2014; Wolf et al., 2008). Freeman (2007) estimates that between $10 \%$ and $15 \%$ of the general population experience paranoid thoughts regularly and, based on reviewed studies, this could be due to negative affect and anxiety. We also now know that there is a relationship between negative affect and anxiety and smoking (Grant, Hasin et al., 2004), which could explain why people with high scores on this scale are more likely to smoke. 
This study is not without limitations. The ability to generalize the results to smokers from the general population is limited because we used a clinical sample of patients who received an intervention to quit smoking. This type of sample has different characteristics, for example, a greater nicotine dependence (Fagerström et al., 1996). Additionally, the data are based on a self-report questionnaire, although the nine Validity scales allow reducing biases such as social desirability or distortions of recall. In addition, the MMPI-2-RF is a screening tool that does not allow performing diagnoses. Moreover, we could not establish comparisons with other studies on the relationship between psychopathology assessed with this instrument and tobacco use, due to its recent publication. Finally, participants with a severe mental disorder were excluded from the total sample, as they follow a different smoking cessation treatment protocol with more sessions.

Despite these limitations, this study adds more knowledge about the MMPI-2RF and shows its utility in the field of the treatment of tobacco use. In addition, we used a sample of smokers who attended a psychological treatment to quit smoking and who were assessed longitudinally for one year, using biochemical validation of tobacco abstinence (CO).

\section{Conclusion}

The results of this study indicate that the MMPI-2-RF is a suitable instrument for the assessment of psychopathology and the prediction of the results of a treatment to quit smoking. Therefore, it can be important for the design and improved outcomes of treatments to quit smoking in future studies.

\section{Funding}


This research was supported by the Spanish Ministry of Economy and

Competiveness (Project reference: PSI2012-31196) and by FEDER (European Regional Development Fund)

\section{References}

Ames, S. C., Vickers, K. S., Decker, P. A., Patten, C. A., Colligan, R. C., VargasChanes, D.,...Offord, K. P. (2005). Select Minnesota Multiphasic Personality Inventory (MMPI) scales as predictors of tobacco abstinence following treatment for nicotine dependence. Psychology and Health, 20, 331-351. doi: $10.1080 / 08870440512331317643$

Andrucci, G. L., Archer, R. P., Pancoast, D. L., \& Gordon, R. A. (1989). The relationship of MMPI and Sensation Seeking Scales to adolescent drug use. Journal of Personality Assessment, 53, 253-266. doi: 10.1207/s15327752jpa5302_4

Aubin, H. J., Rollema, H., Svensson, T. H., \& Winterer, G. (2012). Smoking, quitting, and psychiatric disease: A review. Neuroscience and Behavioral Reviews, 36, 271-284. doi: 10.1016/j.neubiorev.2011.06.007

Ayearst, L. E., Sellbom, M., Trobst, K. K., \& Bagby, R. M. (2013). Evaluating the interpersonal content of the MMPI-2-RF interpersonal scales. Journal of Personality Assessment, 95, 187-196. doi: 10.1080/00223891.2012.730085

Basile, A., Bernazzali, S., Diciolla, F., Lenzini, F., Lisi, G., Maccherini, M.,...Chiavarelli, M. (2004). Risk factors for smoking abuse after heart transplantation. Transplantation Proceedings, 36, 641-642. doi: 10.1016/j.transproceed.2004.02.054

Becoña, E. (1994). Evaluación de la conducta de fumar [Assessment of the smoking behavior]. In J. L. Graña (Ed.), Conductas adictivas: Teoría, evaluación y 
tratamiento [Addicitve behaviors: Theory, assessment, and treatment] (pp. 403-454). Madrid: Debate.

Becoña, E. (2007). Programa para dejar de fumar [Smoking cessation program]. Vigo, Spain: Nova Galicia Edicións.

Becoña, E., Fernández del Río, E., López-Durán, A., Piñeiro, B., \& Martínez, U. (2013). Axis II disorders and cigarette smoking among adults from the general population. Journal of Personality Disorders, 26, 411-424. doi: 10.1521/pedi_2012_26_051

Becoña, E., \& Vázquez, F. L. (1998). The Fagerström Test for Nicotine Dependence in a Spanish sample. Psychological Reports, 83, 1455-1458. doi: 10.2466/pr0.1998.83.3f.1455

Ben-Porath, Y. (2012). Interpreting the MMPI-2-RF. Minneapolis, MN: University of Minnesota Press.

Bolinger, E., Reese, C., Suhr, J., \& Larrabee, G. J. (2014). Susceptibility of the MMPI2-RF Neurological Complaints and Cognitive Complaints scales to overreporting in simulated head injury. Archives of Clinical Neuropsychology, 29, 7-15. doi: $10.1093 / \operatorname{arclin} / \operatorname{act} 082$

Brinker, J. K., Chin, Z. H., \& Wilkinson, R. (2014). Ruminative thought style and personality. Personality and Invidual Differences, 60, S41. doi: 10.1016/j.paid.2013.07.112

Campion, J., Checinski, K., Nurse, J., \& McNeill, A. (2008). Smoking by people with mental illness and benefits of smoke-free mental health services. Advances in Psychiatric Treatment, 14, 217-228. doi: 10.1192/apt.bp.108.005710 
Cottraux, J., Schbath, J., Messy, Ph., Mollard, E., Juenet, C., \& Collet, L. (1986). Predicitve value of MMPI scales on smoking cessation programs outcomes. Acta Psychiatrica Belgica, 86, 463-469.

Ekleberry, S. C. (2009). Integrated treatment for co-occurring disorders: Personality disorders and addiction. New York, NY: Routledge/ Taylor \& Francis Group.

Evans, R. R., Borgatta, E. F., \& Bohrnstedt, G. W. (1967). Smoking and MMPI scores among entering freshmen. Journal of Social Psychology, 73, 137-140. doi: $10.1080 / 00224545.1967 .9712446$

Fagerström, K. O., \& Furberg, H. (2008). A comparison of the Fagerström Test for Nicotine Dependence and smoking prevalence across countries. Addiction, 103, 841-845. doi: 10.1111/j.1360-0443.2008.02190.x

Fagerström, K. O., Kunze, M., Schoberberger, R., Breslau, N., Hughes, J. R., Hurt, R.,...Zatonski, W. (1996). Nicotine dependence versus smoking prevalence: Comparison among countries and categories of smokers. Tobacco Control, 5, 52-56. doi: 10.1136/tc.5.1.52

Fiore, M. C., Jaén, C. R., Baker, T. B., Bailey, W. C., Benowitz, N. L., Curry, S. J.,...Leitzke, C. (2008). Treating tobacco use and dependence: 2008 Update. Rockville, MD: U. S. Department of Health and Human Services, Public Health Service.

Forbey, J. D., \& Ben-Porath, Y. S. (2007). A comparison of the MMPI-2 restructured clinical (RC) and clinical scales in a substance abuse treatment sample. Psychological Services, 4, 46-58. doi: 10.1037/1541-1559.4.1.46

Freeman, D. (2007). Suspicious minds: The psychology of persecutory delusions. Clinical Psychology Review, 27, 425-457. doi: 10.1016/j.cpr.2006.10.004 
Grant, B. F., Hasin, D. S., Chou, P., Stinson, P., Stinson, F. S., \& Dawson, D. A. (2004). Nicotine dependence and psychiatric disorders in the United States: Results from the National Epidemiologic Survey on Alcohol and Related Conditions. Archives of General Psychiatry, 61, 1107-1115. doi:

10.1001/archpsyc.61.11.1107

Grant, B. F., Stinson, F. S., Dawson, D. A., Chou, P., Dufour, M. C., Compton, W.,...Kaplan, K. (2004). Prevalence and co-occurrence of substance use disorders and independent mood and anxiety disorders. Archives of General Psychiatry, 61, 807-816. doi: 10.1001/archpsyc.61.8.807

Hall, S. M., \& Prochaska, J. J. (2009). Treatment of smokers with co-occurring disorders: Emphasis on integration in mental health and addiction treatment setting. Annual Review of Clinical Psychology, 5, 409-431. doi: 10.1146/annurev.clinpsy.032408.153614

Hathaway, S. R., \& McKinley, J. C. (1943). The Minnesota Multiphasic Personality Inventory. Minneapolis, MN: University of Minnesota Press.

Heatherton, T. F., Kozlowski, L. T., Frecker, R. C., \& Fagerström, K. O. (1991). The Fagerström Test for Nicotine Dependence: A revision of the Fagerström Tolerance Questionnaire. British Journal of Addictions, 86, 1119-1127. doi: 10.1111/j.1360-0443.1991.tb01879.x

Hitsman, B., Papandontos, G. D., McChargue, D. E., DeMott, A., Herrera, M. J., Spring, B.,... Niaura, R. (2013). Past major depression and smoking cessation outcome: A systematic review and meta-analysis update. Addiction, 108, 294306. doi: 10.1111/add.12009 
Jaffe, L. T., \& Archer, R. P. (1987). The prediction of drug use among college students from MMPI, MCMI, and sensation seeking scales. Journal of Personality Assessment, 51, 243-253. doi: 10.1207/s15327752jpa5102_8

John, U., Meyer, C., Rumpf, H., \& Hapke, U. (2004). Smoking, nicotine dependence and psychiatric comorbidity. A population-based study including smoking cessation after three years. Drug and Alcohol Dependence, 76, 287-295. doi: 10.1016/j.drugalcdep.2004.06.004

Lasser, K., Boyd, J. W., Woolhandler, S., Himmelstein, D. U., McCormick, D., \& Bor, D. H. (2000). Smoking and mental illness: A population-based prevalence study. JAMA, 284, 2606-2610. doi: 10.1001/jama.284.20.2606

Leon, G. R., Kolotkin, R., \& Korgeski, G. (1979). MacAndrew Addiction Scale and other MMPI characteristics associated with obesity, anorexia and smoking behavior. Addictive Behaviors, 4, 401-407. doi: 10.1016/0306-4603(79)90011$\mathrm{X}$

Lipkus, I. M., Bareffot, J. C., Williams, R. B., \& Siegler, I. C. (1994). Personality measures as predictors of smoking initiation and cessation in the UNC Alumni Heart Study. Health Psychology, 13, 149-155.

Piñeiro, B., Fernández del Río, E., López-Durán, A., Martínez, U., \& Becoña, E. (2013). The association between probable personality disorders and smoking cessation maintenance. Addictive Behaviors, 38, 2369-2373. doi: 10.1016/j.addbeh.2013.03.017

Purdon, S. E., Purser, S. M., \& Goddard, K. M. (2011). MMPI-2 restructured form over-reporting scales in first-episode psychosis. Clinical Neuropsychology, 25, 829-842. doi: 10.1080/13854046.2011.585141 
Rüther, T., Bobes, J., De Hert, M., Svensson, T. H., Mann, K., Batra, A.,...Möller, H. J. (2014). EPA Guidance for smoking on tobacco dependence and strategies for smoking cessation in people with mental illness. European Psychiatry, 29, 6582. doi: 10.1016/j.europsy.2013.11.002

Samuel, D. B., \& Widiger, T. A. (2008). A meta-analytic review of the relationships between the five-factor model and DSM-IV-TR personality disorders: A facet level analysis. Clinical Psychology Review, 28, 1326-1342. doi: 10.1016/j.cpr.2008.07.002

Sellbom, M., Bagby, R. M., Kushner, S., Quilty, L. C., \& Ayearst, L. E. (2012). Diagnostic construct validity of MMPI-2 Restructured Form (MMPI-2-RF) scale scores. Assessment, 19, 176-186. doi: 10.1177/1073191111428763

Simms, L. J., Casillas, A., Clark, L. A., Watson, D. \& Doebbeling, B. N. (2005). Psychometric evaluation of the restructured clinical scales on the MMPI-2. Psychological Assessment, 17, 345-358. doi: 10.1037/1040-3590.17.3.345

Tappan, D. V., \& Weybrew, B. B. (1982). Relationship of personality factors and some social habits to cardiovascular risk in submariners. Aviation, Space, and Environmental Medicine, 53, 383-389.

Tellegen, A., \& Ben-Porath, Y. (2008/2009). The Minnesota Multiphasic Personality Inventory-2 Restructured Form: Technical Manual. Minneapolis, MN: University of Minnesota Press. (Spanish version: Inventario Multifásico de Personalidad de Minnesota-2 Reestructurado. Ben-Porath, Y. S., \& Tellegen, A. 2009. Madrid: Tea Ediciones).

Tian, J., Venn, A. J., Blizzard, L., Patton, G. C., Dwyer, T., \& Gall, S. L. (in press). Smoking status and health-related quality of life: A longitudinal study in young adults. Quality of Life Research. doi: 10.1007/s11136-015-1112-6 
U.S.D.H.H.S. (2014). The health consequences of smoking-50 years of progress. A report of the Surgeon General. Rockville, MD: U. S. Department of Health and Human Services, Public Health Services, Office of the Surgeon General.

van der Heijden, P. T., Egger, J. I. M., \& Derksen, J. J. L. (2008). Psychometric evaluation of the MMPI-2 restructured clinical scales in two Dutch samples. Journal of Personality Assessment, 90, 456-464. doi: $10.1080 / 00223890802248745$.

van der Heijden, P. T., Egger, J. I. M., Rossi, G. M., \& Derksen, J. J. L. (2012). Integrating psychopathology and personality disorders conceptualized by the MMPI-2-RF and the MCMI-III: A structural validity study. Journal of Personality Assessment, 94, 345-357. doi: 10.1080/00223891.2012.656861

Velicer, W. F., Prochaska, J. O., Rossi, J. S., \& Snow, M. G. (1992). Assessing outcome in smoking cessation studies. Psychological Bulletin, 111, 23-41. doi: 10.1037/0033-2909.111.1.23.

West, R., Hajek, P., Stead, L., \& Stapleton, J. (2005). Outcome criteria in smoking cessation trials: Proposal for a common standard. Addiction, 100, 299-303. doi: 10.1111/j.1360-0443.2004.00995.x

Wolf, E. J., Miller, M. W., Orazem, R. J., Weierich, M. R., Castillo, D. T., Milford, J.,...Keane, T. M. (2008). The MMPI-2 Restructured Clinical Scales in the assessment of posttraumatic stress disorder and comorbid disorders. Psychological Assessment, 20, 327-340. doi: 10.1037/a0012948 
Table 1. Sociodemographic characteristics of the sample of smokers $(N=281)$.

\begin{tabular}{|c|c|c|}
\hline & Mean & $S D$ \\
\hline \multirow[t]{2}{*}{ Age } & 41.80 & 10.78 \\
\hline & $\mathrm{n}$ & $\%$ \\
\hline \multicolumn{3}{|l|}{ Age (grouped) } \\
\hline$\leq 40$ & 123 & 43.8 \\
\hline$>40$ & 158 & 56.2 \\
\hline \multicolumn{3}{|l|}{ Gender } \\
\hline Male & 111 & 39.5 \\
\hline Female & 170 & 60.5 \\
\hline \multicolumn{3}{|l|}{ Marital status } \\
\hline Single & 94 & 33.5 \\
\hline Married/living with partner & 146 & 52.0 \\
\hline Separated or divorced & 33 & 11.7 \\
\hline Widowed & 8 & 2.8 \\
\hline \multicolumn{3}{|l|}{ Educational level } \\
\hline Elementary & 65 & 23.1 \\
\hline Middle studies & 96 & 34.2 \\
\hline Higher studies & 120 & 42.7 \\
\hline \multicolumn{3}{|l|}{ Social class } \\
\hline Low & 66 & 23.5 \\
\hline Medium & 188 & 66.9 \\
\hline High & 27 & 9.6 \\
\hline
\end{tabular}


Table 2. Comparison of age, nicotine dependence, and MMPI-2-RF scales between smokers and abstainers at the end of treatment and at the 6- and 12- months follow-ups.

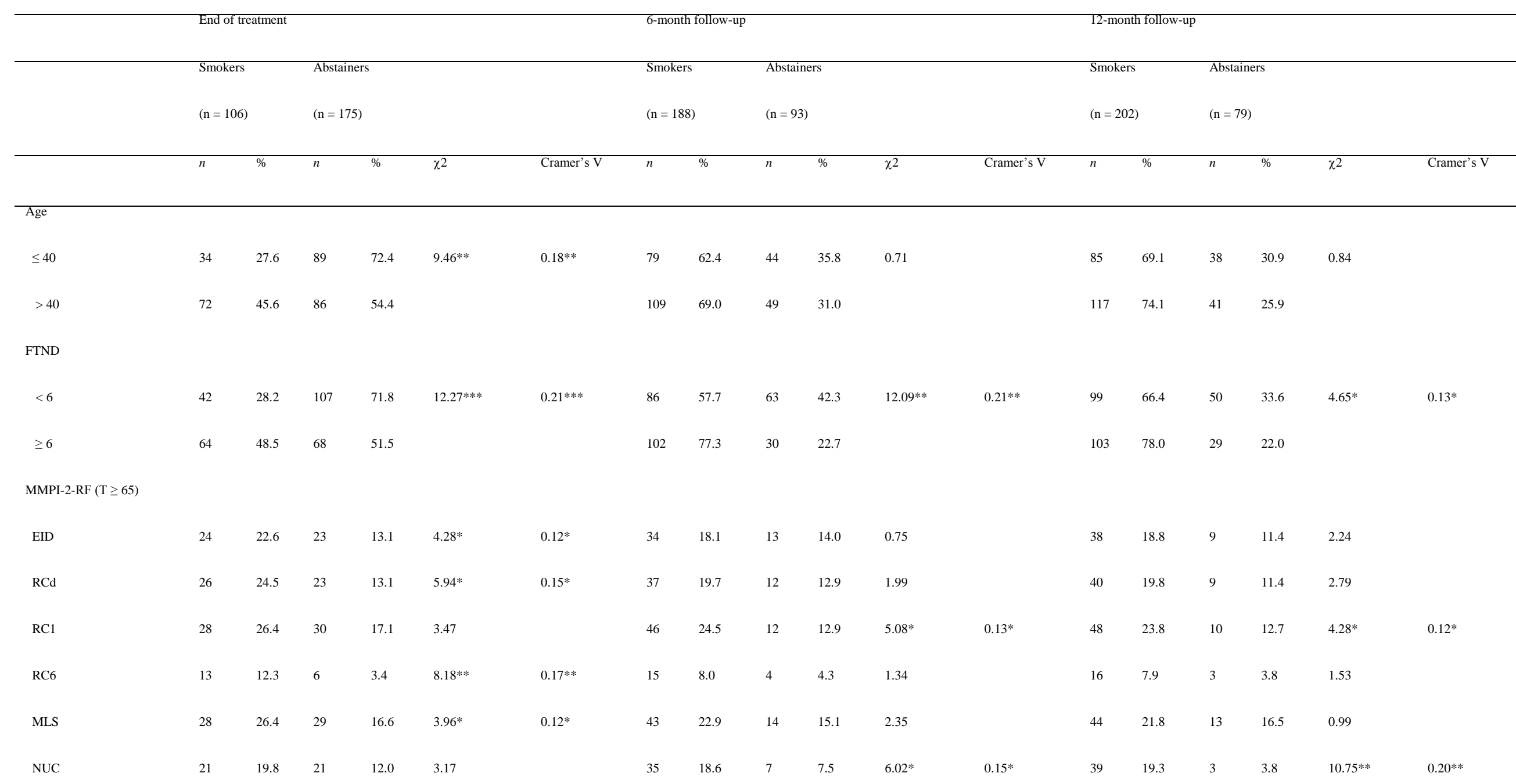




\begin{tabular}{|c|c|c|c|c|c|c|c|c|c|c|c|c|c|c|c|c|}
\hline COG & 27 & 25.5 & 23 & 13.1 & $6.86^{* * *}$ & $0.16^{* * *}$ & 39 & 20.7 & 11 & 11.8 & 3.38 & 41 & 20.3 & 9 & 11.4 & 3.09 \\
\hline SFD & 20 & 18.9 & 17 & 9.7 & $4.83^{*}$ & $0.14 *$ & 28 & 14.9 & 9 & 9.7 & 1.48 & 29 & 14.4 & 8 & 10.1 & 0.89 \\
\hline NFC & 19 & 17.9 & 14 & 8.0 & $6.27^{*}$ & $0.15^{*}$ & 26 & 13.8 & 7 & 7.5 & 2.39 & 25 & 12.4 & 8 & 10.1 & 0.28 \\
\hline AXY & 21 & 19.8 & 17 & 9.7 & $5.76^{*}$ & $0.14 *$ & 28 & 14.9 & 10 & 10.8 & 0.91 & 31 & 15.3 & 7 & 8.9 & 2.04 \\
\hline DSF & 13 & 12.3 & 3 & 1.7 & $13.68 * * *$ & $0.22 * * *$ & 13 & 6.9 & 3 & 3.2 & 1.58 & 14 & 6.9 & 2 & 2.5 & 2.05 \\
\hline PSYC-r & 7 & 6.6 & 2 & 1.1 & $6.35^{*}$ & 0.15 & 8 & 4.3 & 1 & 1.1 & 2.03 & 9 & 4.5 & 0 & 0.0 & 3.64 \\
\hline
\end{tabular}

(1) Fisher's exact test was used when the expected values of at least $20 \%$ of the cells were less than 5.

EID: Emotional/Internalizing Dysfunction; RDd: Demoralization; RC1: Somatic Complaints; RC6: Ideas of Persecution; MLS: Malaise; NUC: Neurological Complaints; COG: Cognitive Complaints; SFD: Self-Doubt; NFC: Inefficacy; AXY: Anxiety; DSF: Disaffiliativeness; PSYC-r: Psychoticism-Revised.

$* p \leq .05 . * * p \leq .01 . * * * \leq .00$. 
Table 3. Variables predicting smoking at the end of treatment and at the 12-month follow-up.

AOR $\quad 95 \% \mathrm{CI}$ p-value

End of treatment

$\begin{array}{llll}\mathrm{DSF}(\mathrm{T} \geq 65) & 0.15 & 0.035-0.604 & .008\end{array}$

12-month follow-up

$\begin{array}{llll}\mathrm{NUC}(\mathrm{T} \geq 65) & 5.60 & 1.476-21-250 & .011\end{array}$

AOR: Adjusted Odd Ratio for age and initial level of nicotine dependence.

DSF: Disaffiliativeness; NUC: Neurological Complaints

6

7

8 